\title{
Genre-Based Analysis of American Tourism Brochure
}

\author{
Jing Luo, Tingyu Huang \\ Shenzhen Tourism College, Jinan University, Shenzhen, China \\ Email: ivyluojing@163.com, TingyuHUANG93@hotmail.com
}

Received 14 August 2015; accepted 14 September 2015; published 17 September 2015

Copyright (C) 2015 by authors and Scientific Research Publishing Inc.

This work is licensed under the Creative Commons Attribution International License (CC BY). http://creativecommons.org/licenses/by/4.0/

(c) (i) Open Access

\begin{abstract}
The language in tourism brochure can help to construct destination's image in reader's mind. In this paper, 35 tourism brochures collected from more than 20 renowned attractions in western America have been selected as the corpus. On basis of English for Special Purpose School's genre analysis theory, this article makes an attempt to generalize a specific generic structure for tourism brochure with eight moves by utilizing Bhatia's move-structural model in advertisement as the theoretical framework. In addition, an innovative cross-disciplinary trial has been made to combine genre analysis with the formation process of tourist destination image. Moves and strategies with the communicative purpose of shaping destination image are thereby emphasized. Through organizing the generic feature of American tourism brochure, enlightenment of typical strategies in the discourse production for domestic tourism brochure will be concluded.
\end{abstract}

\section{Keywords}

Tourism Brochure, Genre Analysis, Move-Structural Model, Tourist Destination Image

\section{Introduction}

Recent decades have witnessed a rapid growth in tourism industry, and the publicity of tourist destination is in consequence drawing scholars' attention. Functioning as the information carrier to publicize tourist destination image, the analysis of tourism brochure in applied linguistics field should be given concerns.

This study on tourism brochure discourse is established on the basis of English for Special Purpose (ESP) School's theory from the perspective of genre analysis, taking the aim at discussing how discourse should be structured in the writing process. Since genre (or generic structure) is inseparable from the communicative purpose of discourse behavior, genre analysis of tourism brochure targets at building and promoting the tourist destination image. In this article, through a comprehensive, in-depth genre analysis of 35 tourism brochures col- 
lected from famous scenic spots in western America, a typical generic structure of tourism brochure is made to show how a series of rhetorical moves and strategies build and popularize the tourist destination image. Thereby enlightenment of general strategies, and techniques in the practical writing process for domestic tourism brochures could be found.

\section{Literature Review}

\subsection{Genre Analysis}

In applied linguistics field, the study on genre can be divided into three major schools: Australian Systemic Function School, North American New Rhetoric School and English for Special Purpose (ESP) School [1]. Differing from other two schools' emphasis on linguistics function and social or situational context, ESP School's genre analysis is set from pedagogic perspective on language usage in professional settings, e.g. generic analysis of academic paper, job application letter, sales promotion letter, legislative provisions, etc. In ESP School, genre is defined as "a recognizable communicative event characterized by a set of communicative purposes identified and mutually understood by the members of a professional or academic community in which it regularly occurs. It is highly structured and conventionalized with constraints within the framework of socially recognized purposes" [2]. In 1981, Swales with his pioneering study on the introduction of academic articles initially proposed CARS (Create A Research Space) model, he notices a rhetorical pattern that forms genre by identifying a series of moves and steps, proposes that a move is a unit that serves to accomplish the communicative purpose of discourse behavior and gives it a typical structure, a step is a lower level text unit than move which help move achieve its function.

In Swales' definition, move structures are prototypes that can be varied according to the conventionalized genre [3]. Thus Bhatia develops CARS model by bringing cognitive facts and begins to summarize the generic structure in application writing. Through primarily studies on sales promotion letter and job application letter, he proposes a universal move-structural model for promotional genre (Table 1). In this model, steps are replaced by the term "strategy" to explain the way of the specific realization or construction of the move. Through a clear classification on genre, advertisement has been divided into the range of sub-genre under promotional genre, Bhatia then develops a model in advertisement with nine rhetorical moves and subdivided strategies listed in sequence.

So far, genre analysis on tourism discourse is gradually drawing scholars' attention. During 1990s, Alex Henry and Robert L. Roseberry initially employed related genre analysis approach to study "Brief Tourist Information", generic structure and lexical terms shown in their paper lay the foundation for further researches. Recent years, domestic scholars are also shifting their emphasis to this field. Some scholars such as Chen Yinxiao and Luo Xianqing analyze targets at local tourism resources [5] [6]. While Dai Xiulan and Jiang Lei take contrastive analysis on tourism discourse from different region [7] [8]. However, very few genre analysis of tourism discourse has focused on American tourism brochure, so the novelty of the research object could be guaranteed.

\subsection{Tourist Destination Image}

The definition of tourist destination image (or destination image) is very vague, but currently-acknowledged de-

Table 1. Move-structural model of advertisement [4].

\begin{tabular}{cc} 
Move 1 & Headlines/Attracting readers' attention \\
Move 2 & Targeting the market \\
Move 3 & Justifying the product or service \\
Move 4 & Detailing the product or service \\
Move 5 & Establishing credentials \\
Move 6 & Celebrity or typical user endorsement \\
Move 7 & Offering incentives \\
Move 8 & Using pressure tactics \\
Move 9 & Soliciting responses \\
\hline
\end{tabular}


scription is "an individual's mental representation of beliefs, feelings and overall perceptions towards a destination which is not his residence” [9]. Michael Grosspietsch clears his definition into two parts: a perceived image presenting tourist's anticipation towards the destination and a projected image coming from the destination constructed for potential visitors. Gunn further elaborates two stages to form the perceived image. Stage 1: organic image influenced by potential visitor's former experience or media publicity strategies; Stage 2: induced image formed by tourist destination's promotion campaign [10]. Fakeye and Crompton enriches Gunn's theory by adding "complex image" as Stage 3, which refers to an overall impression tourist possessing after the visiting experience [11].

Fakeye and Crompton also point out the connection between tourist destination image and tourism advertising. In accordance with three stages of tourist destination image, different advertising strategies should be made separately: The first stage need to focus on the informative function, providing all-round information about the destination to impress potential customers. The second stage moves to the persuasive function structuring a virtuous induced image to ensure customer's visit. Then the final stage highlights on reminding visitors of revisiting.

Due to the fact that studies on tourist destination image are mostly confined to the tourism academic field, very few of them include the cross-disciplinary analysis on tourism discourse. Also, through studying the previous research findings, it is obviously indicated that the studies towards tourism discourse are similarly restricted to the linguistic field. Hence this article makes a trial to connect genre analysis of tourism brochure with the publicity of tourist destination image thereby making proposals for the improvement on brochure writing.

\section{Data Collection and Analysis}

\subsection{Data Collection}

35 samples selected for this research are all print-form tourism brochures picked from hotel reception or information office of renowned scenic spots attractions within western America, e.g. San Francisco, Los Angeles, San Diego, Carmel by-the-sea, Grand Teton National Park, Yellowstone National Park, Bryce Canyon National Park, Glen Canyon National Park, etc.

To ensure the validity of the study, all selected brochures are guaranteed to be officially published. Since tourism advertisements shows a large diversity, leaflets, pamphlets, booklets are all engaged in this research. Also, the wide type of the tourist destination requires that both humanity and natural scenic spots should be included. The contents are divided into several kinds: guide book, local resource reference, road map, etc.

\subsection{Analysis}

\subsubsection{Move-Structural Model of Tourism Brochure}

According to Bhatia's classification on genre and sub-genres, tourism brochure presenting as a print-form ad, is divided into the sub-genre of advertisement. Namely, the communicative purpose of tourism brochure overlaps with that of advertisement, but slight differences distinguish because of the features of context. Consequently, the genre analysis on tourism brochure should be made on basis of Bhatia's move-structural model of advertisement. Through discovering the specific feature of selected samples, some moves and strategies in Bhatia's model would be adjusted to form a generic structure applied in tourism brochure.

In Swales' words, tactical moves and steps could be changed within allowable boundaries of certain genre to fulfill different communicative purposes, the set of move and step must be accordance with discriminative communicative purposes [12]. To identify a specific move-structural model for tourism brochure, it is an essential procedure to compare the communicative purposes of tourism brochure with those of advertisement. Following four divergences between two genres has been listed via a brief comparison. 1) The communicative purposes of general advertisement emphasize on persuading behavior that aims to promote the product or service and to motivate purchase. However, tourism brochure also shows a large proportion on informing and reminding functions. 2) The promotion objectives in two genres are different. For regular advertisement, potential customers are blind to the product or service with very limited understanding toward it, "justifying" and "detailing" the product or service ahead is the fundamental procedure. Whereas for tourism brochure, the formation of organic image and certain tourist incentives coming from potential visitors guarantee the accessibility of brochure, "establishing credentials" is the essential process to guarantee further reading. 3) In general advertisement, persuasive behavior takes up a large percentage, while this function has been slightly weaken in tourism brochure. 
Through analysis, very few give endorsements from media or former visitors, and none utilize pressure tactics. 4) One of the original functions of tourism brochure is to provide service information which is not necessary in other forms of advertisements.

Therefore, some modifications applied in tourism brochure are presented in Table 2. 1) After "attracting reader's attention" on the cover page and "targeting the market" in the brief introduction section, "establishing credentials" should be put forward to ensure visitor's further reading, following by detailed descriptions of the tourist destination. 2) The move of "justifying product or service" in advertisement could be specified as "highlighting the specialties" for the main product in tourism brochure generally refers to special attractions. 3) Move 5 and 6 in advertisement both concentrate on convincing underlying customers to impulse their purchasing behavior. In the modified model, "celebrity or typical user endorsement" is classified as a strategy under the "establishing credentials" move. 4) No pressure tactics have been shown in the samples. Since informative and reminding purposes take up a large proportion in the tourism brochure conducting, the high occurrence frequency of "providing service information" coming after the promotion part is made as a replacement of move 8 in advertisement.

\subsubsection{Analysis of Move 1: Attracting Tourists' Attention}

In tourism brochure, discourse of Move 1 is generally displayed on the cover page like headlines, subheadings and brief descriptions. Differing from other forms of ads, tourism brochure distinguishes in its acquisition channel. Tourists get the brochure from public areas within the tourist destination, which means tourists have formed a brief organic image towards the destination. Content in this move must be highly informative to provide convenience to make further search. Here, two major strategies have been summarized as follows:

1) By giving the name of tourist destination

a) BAY CITY GUIDE-EXPLORE SAN FRANCISCO

b) City Sightseeing San Francisco

All tourism brochures present the name of tourist destination in the headline to actualize the informative purpose. Two titles are both picked from San Francisco brochures, it can be indicated that Example 1 is a general tourist guide while the latter is fixed at a city sightseeing.

\section{2) By highlighting specialties}

c) TOURS IN SAN FRANCISCO

- YOSEMITE TRAIN TOURS

- PREMIUM WINE TOURS

- MUIR WOODS TOURS

Highlighting specialties on the cover page is also a customary strategy to attract readers' interest. By noticing renowned attractions, designed itineraries or special themes, readers will update their organic image, integrate the strengths or specialties after browsing these key points.

To sum up, acting as an informative part, Move 1 mainly functions to specify an accurate organic image for tourists in the destination image building process.

\subsubsection{Analysis of Move 2: Targeting the Market}

For tourist destinations, the structure of image must be made according to visitors' organic preferences or antic-

Table 2. Comparative generic structure of advertisement and tourism brochure.

\begin{tabular}{ccc}
\hline & Advertisement & Tourism Brochure \\
\hline Move 1 & Attracting readers’ attention & Attracting tourists’ attention \\
Move 2 & Targeting the market & Targeting the market \\
Move 3 & Justifying the product or service & Establishing credentials \\
Move 4 & Detailing the product or service & Highlighting specialties \\
Move 5 & Establishing credentials & Detailing the tourist destination \\
Move 6 & Celebrity or typical user endorsement & Offering incentives \\
Move 7 & Offering incentives & Providing service information \\
Move 8 & Using pressure tactics & Soliciting responses \\
Move 9 & Soliciting responses & \\
\hline
\end{tabular}


ipations. The same principal is applied in tourism brochure writing process. The communicative purpose of this move is to offer specific messages for distinct target groups according to their needs. Distinguished strategies of targeting groups help specify the organic image for diverse potential consumers.

1) By defining keywords

a) CARMEL

DOG-FRIENDLY TOUR \& ECO-FRIENDLY TOUR

Two keywords are picked from the Welcome to Carmel section, by highlighting two novel features, pet owners and environmentalists are targeted, a clear and definite image will be build to enrich their organic understanding. Informative keywords usually evoke the interest of target group to make further information search.

\section{2) By defining theme of tour}

b) Content of CARMEL:

The Great Outdoors

Wining and Dining

Be Enlightened by Arts

History Buff

Here, four diverse tours are designed with reference to tourists' various preferences, four special groups of potential customers are targeted: outdoor sports lover, wine taster, art lovers, and history buffs. The classification of different theme works for refining the organic image of target groups.

\subsubsection{Analysis of Move 3: Establishing Credentials}

In Fakeye and Crompton's model, after forming a basic organic image of the destination, target customers will enrich their previous perceived understanding, reform a detailed induced image. The emphasis transits from informative to persuasive purpose in this move, discourse should consist of elaborated descriptions presenting the uniqueness, positive comments from authoritative critics or feedbacks from former visitors to establish credentials. Thus, a virtuous image will be injected.

1) By indicating the value of the tourist destination

a) Carmel

The most significant mention received was that of Monterey County being designed as one of the top 10 wine destinations in the world, and Carmel is the only destination in California to make the list!

In this description, promotional words like "top 10", “only” could be seen as suggestive and persuasive points to readers, successfully display Carmel's significance and uniqueness in wine and taste tour. The strategy of indicating values is effective on inducing a worth-traveling image for visitors.

2) By giving endorsement

b) Camel

Carmel was rated \#3 in the list of the world's best cities for romance.

Endorsement refers to social recognitions, such as positive comments of authorities or feedbacks from former visitors. Due to the authenticity of message, it is the most convincing strategy to establish a reliable image in the induced-image building process.

\subsubsection{Analysis of Move 4: Highlighting Specialties}

In this move, the communicative purpose of this practice is more persuasive, the target shifts to promote an all-round induced image by pointing out the outstanding projects, the ultimate goal is to persuade tourists to choose the destination.

a) Muir Woods \& Sausalito

Old Growth Coast Redwood Trees

1000 Years Old-Tallest Trees in the World

b) Starry Night in Bryce Canyon

High elevation, clean dry air, and the lack of light pollution make Bryce Canyon one of the world's darkest places. Bryce Canyon offers you ultimate stargazing. Powerful telescopes reveal the new stars inside nursery nebulae, shock waves from exploded stars, and ancient globular clusters seems like diamond on black velvet.

The specialties have been underlined, In Example 8, the copywriter uses bold-form keywords to mark the specialty. In Example 9, the specialty is given literarily with beautiful description. Marking words and phrases is very common in tourism brochures, while Example 9's method is widely used by natural scenic spots. Each 
form in Move 4 shapes a specialized image through bringing specialties to ensure tourist’s visit.

\subsubsection{Analysis of Move 5: Detailing the Tourist Destination}

In Bhatia's theory, each promotional genre is centralized on this move, as it can realize the generic values of "description" and "evaluation". Here, the communicative purpose of Move 5 expends to persuasive level, a thorough introduction should be made in accordance with reader's interest to rebuild a detailed and idiographic induced image. Two strategies have been extracted from sample brochures.

\section{1) By introducing the tourist destination}

a) Glen Canyon

The introduction part (omitted)

Essential background information involving multiple aspects is given in the introduction: the establishment of Glen Canyon National Recreation Area, the constitution of Glen Canyon, the entertaining activities as well as the historical, geological, paleontological and ecological value. History, geology, paleontology and ecology background are also mentioned in the detailed introduction section. Same introduction structure and content are shown in other national parks brochures as well.

\section{2) By recommending itineraries}

b) Yellowstone

Tour 1: Old Faithful to Mammoth Hot Spring

Tour 2: Tower-Roosevelt and Canyon Village

Detailed descriptions regarding history, geology, ecology background of each tour are omitted here. Generally, the strategy of recommending itinerary with details contributes to shape a thorough and concretized destination image.

Move 5 with the function of offering details of tourist destination is the most vital part in the generic structure. Compared with the former moves informing a clear organic image for potential visitors, this move is specialized in providing an idiographic and comprehensive induced image with various perspectives to motivate tourists.

\subsubsection{Analysis of Move 6: Offering Incentives}

Here, the object of this move is promotional behaviors from tourist destinations, other business seller's relevant commercial advertisements are not included. Through analysis, two typical tactics have been organized as follows:

1) By providing preferential policy

a) Become a USS Midway Member!

Get discounts and bring friends and family back all year long for FREE!

Preferential policy usually contains discounts, attached package and membership system, drawing up preferential policy is a very common strategy to motivate potential visitors. Readers will easily link the tourist destination with a generous and considerate image.

2) By providing additional service

b) Napa \& Sonoma Valley Tour

FREE Hotel Pick-Up \& Drop-Off

Additional services also serve as a motivation providing convenience of facility or service. Through offering additional benefits, considerate service to satisfy consumers, a better overall image will be induced in the second stage of image building procedure.

\subsubsection{Analysis of Move 7: Providing Service Information}

One of the original functions of tourism brochure is to provide valid service information. Move 7 is thereby added to actualize this original function. In this stage, potential visitors have already sketched an integrated image, destination needs to provide services and to solicit response to remind a complex image. Through summarizing, three types of service information are listed below.

a) BIG BEAR SNOW SHOW

LOCATION: 42825 Big Bear Blvd., Big Bear Lake

HOUR: Nov-April: Daily 10 a.m.-4 p.m.

RATES: \$25 per person, unlimited rides, inner tube included

b) Bryce Canyon Service Information (detail omitted) 


\section{ACCESSIBILITY \\ FOR YOUR SAFETY \\ REGULATIONS \\ EMERGENCIES}

Guidance, notice and warning are summarized as three major forms of service information displayed in 35 sample brochures, the content of these service information aims to impress visitors with a considerate customercentered image.

\subsubsection{Analysis of Move 8: Soliciting Responses}

Move 8 is acknowledged as an obligatory move in the structure of any promotional genre. In tourism brochure, to fulfill the reminding purpose, tourism brochures publish contacting information like addresses, telephone numbers, official website, and social network accounts (e.g. facebook, twitter) to offer emergency help or to get feedback; some destinations also deliver welcome or invitation to remind visitor's revisiting.

Big Bear Lake

Welcome to Big Bear Lake!

- 800-424-4232

- BIGBEAR.COM

- 630 Bartlett Road/P.O. Box 1936, Big Bear Lake, CA 92315

- FOLLOW US!

facebook: VisitBigBear

twitter: @BigBearLake

The practice of soliciting response usually can create a virtuous complex image with warm and thoughtful service. For visitors, a perfect perceived image will stimulate revisit.

\subsection{Language and Image Building}

On basis of qualitative and quantitative analysis of 35 sample brochures, features of the generic structure in American tourism brochure have been shown in the following Table 3.

Table 3. Distribution and frequency of moves and strategies in tourism brochure.

\begin{tabular}{|c|c|c|c|c|}
\hline \multicolumn{2}{|r|}{ Move \& Strategy } & \multicolumn{2}{|c|}{ Frequency } & \multirow[t]{2}{*}{ Feature } \\
\hline & Attracting tourists’ attention & 35 & $100 \%$ & \\
\hline \multirow[t]{3}{*}{ Move 1} & Giving the name of tourist destination & 35 & $100 \%$ & Obligatory \\
\hline & Highlighting specialties & 21 & $60 \%$ & \\
\hline & Targeting the market & 10 & $29 \%$ & \\
\hline \multirow[t]{3}{*}{ Move 2} & Defining keywords & 2 & $6 \%$ & Optional \\
\hline & Defining theme of tour & 10 & $29 \%$ & \\
\hline & Establishing credentials & 28 & $80 \%$ & \\
\hline \multirow[t]{2}{*}{ Move 3} & Indicating the value of tourist destination & 28 & $80 \%$ & Optional \\
\hline & Giving endorsement & 5 & $14 \%$ & \\
\hline \multirow[t]{2}{*}{ Move 4} & Highlighting specialties & 33 & $94 \%$ & Optional \\
\hline & Detailing the tourist destination & 35 & $100 \%$ & \\
\hline \multirow[t]{3}{*}{ Move 5} & Introducing the tourist destination & 35 & $100 \%$ & Obligatory \\
\hline & Recommending itineraries & 12 & $34 \%$ & \\
\hline & Offering incentives & 27 & $77 \%$ & \\
\hline \multirow[t]{2}{*}{ Move 6} & Providing preferential policy & 22 & $62 \%$ & Optional \\
\hline & Providing additional service & 8 & $23 \%$ & \\
\hline Move 7 & Providing service information & 35 & $100 \%$ & Obligatory \\
\hline Move 8 & Soliciting responses & 35 & $100 \%$ & Obligatory \\
\hline
\end{tabular}




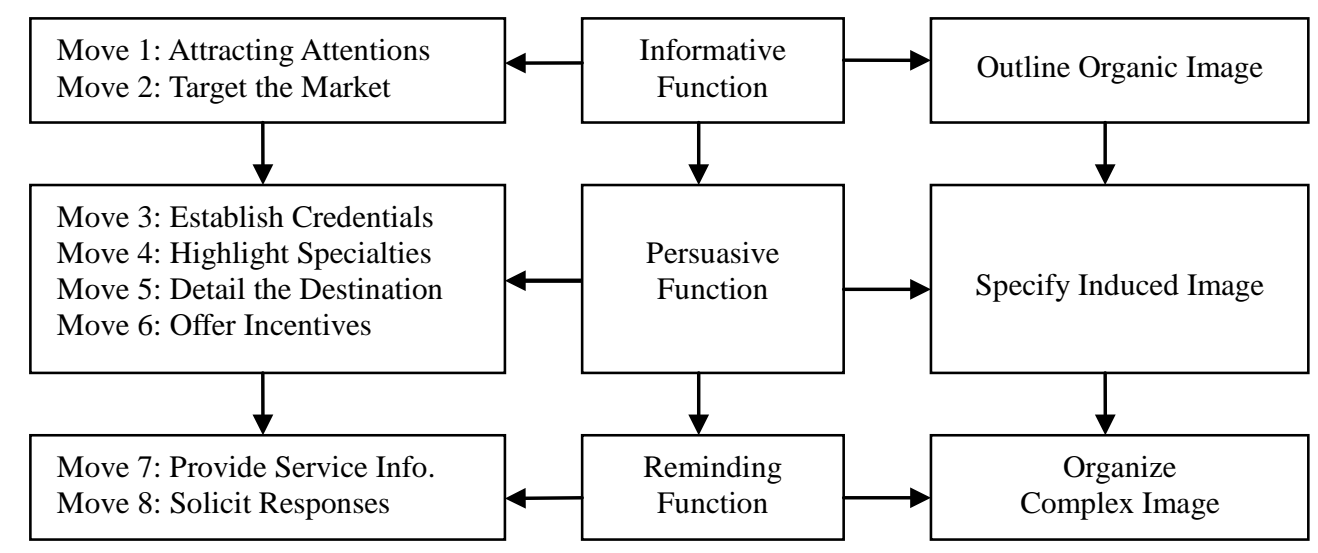

Figure 1. Diagram of generic structure and destination image building process.

According to statistics, Move 1, 5, 7, 8 are featuring as obligatory moves which majorly constitute the generic structure of American tourism brochure while other four moves are optional. Meanwhile, subdivided strategies are also spotlighted to fulfill the communicative function of each move.

Further, the publicity of tourist destination image could be connected with the generic structure of tourism brochure by using three major communicative purposes as the linking points (see Figure 1). To fulfill the informative function, Move 1 and 2 should be designed to inform a clear and specific image which helps potential visitors to refine their organic image towards the destination. To realize the persuasive function, Move 3 to 6 with various strategies need to induce a worth-traveling and favorable image by introducing details and specialties in reader's decision making process. To actualize the reminding function, Move 7 and 8 should serve to remind people of a virtuous complex image that motives revisit.

From ESP school's pedagogical prospective, the findings weigh on the guidance of tourism brochure writing, each move and strategy with precise purpose of structuring tourist destination image make proposals for the improvement on brochure discourse production.

\section{Conclusion}

On basis of qualitative and quantitative analysis of 35 sample brochures, a specific generic structural model for tourism brochure along with distribution features of moves and strategies has been summarized. The result of this study indicates that American tourism brochures apply an eight-move generic model in order: Move 1: attracting tourists' attention; Move 2: targeting the market; Move 3: establishing credentials; Move 4: highlighting specialties; Move 5: detailing the tourist destination; Move 6: offering incentives; Move 7: providing service information; Move 8: soliciting responses. Data of the occurrence frequency of each move and strategy demonstrate that Move 1, 5, 7, 8 are functioning as essential practices in brochure writing process while Move 2, 3, 4, 6 are alternative actions with contributions to the effectiveness of promoting destination image. Moreover, the innovation point of this thesis stands out at the discussion of the connection between the move structure and the process of building tourist destination image. Move 1 and 2 are designed to inform a clear and specific image which helps potential visitors to refine their organic image towards the destination. Move 3 to 6 with various strategies target to induce a worth-traveling and favorable image by introducing details and specialties in reader's decision making process. Move 7 and 8 are serving to remind people of a virtuous complex image that motives revisit. From the pedagogical prospective, the findings weigh on the teaching of English for Special Purposes (ESP) in tourism brochure writing; each move and strategy with precise purpose of structuring tourist destination image can make proposals for the improvement on brochure creation.

\section{References}

[1] Henry, A. and Robert, L.R. (1996) A Corpora-Based Investigation of the Language and Linguistic Patterns of One Genre and the Implication for Language Teaching. Research in the Teaching of English, 5, 472-489.

[2] Bhatia, V.K. (1993) Analyzing Genre: Language Use in Professional Settings. Longman, London.

[3] Swales, J.M. (1990) Genre Analysis: English in Academic and Research Settings. Cambridge University Press, Cam- 
bridge.

[4] Bhatia, V.K. (2004) Worlds of Written Discourse. Continuum, London.

[5] Chen, Y.X. (2010) A Genre Analysis of English Tourist Information Text on the Internet. Dissertation, Shaanxi Normal University, Xi'an.

[6] Luo, X.Q. (2013) A Genre Analysis of English Tourist Information Texts of Tibetan Destinations. Dissertation, Lanzhou Polytechnic University, Lanzhou.

[7] Dai, X.L. (2006) 'Selling' or 'Telling'-A Genre-Based Comparative Analysis of Tourism Information Texts in English and Chinese. Dissertation, Jilin University, Jilin.

[8] Jiang, L. (2009) A Contrastive Genre Analysis of Scenic Spot Texts in China and Singapore. Dissertation, Chongqing University, Chongqing.

[9] Hunt, J.D. (1971) Image-A Factor in Tourism. Colorado State University Press, Colorado.

[10] Gunn, C. Vacationscapes. (1988) Designing Tourist Regions. Van Vostrand Reinhold, New York.

[11] Fakeye, P.C. and Cromopton, J.L. (1991) Image Difference between Prospective, First-Time, and Repeat Visitors to the Lower Rio Grande Valley. Journal of Travel Research, 30, 10-16. http://dx.doi.org/10.1177/004728759103000202

[12] Swales, J.M. (2004) Research Genres: Exploration and Application. Cambridge University Press, Cambridge. http://dx.doi.org/10.1017/CBO9781139524827 